\title{
Ecos visuais no youtube
}

///////////I Ana Paula da Rosa ${ }^{1}$

1. Jornalista, doutora em Ciências da Comunicação pela Unisinos, mestre em Comunicação e Linguagens pela UTP. Atualmente é professora e pesquisadora na Universidade Tecnológica Federal do Paraná (UTFPR). E-mail: anarosa208@yahoo.com.br. 
Resumo Esse artigo visa investigar como se dá o processo de circulação das imagens intermidiáticas. Parte-se da ideia de que muitas fotos jornalísticas são reapropriadas e reinscritas na midiatização, de modo que a memória iconográfica individual vai sendo substituída ou abastecida a partir da manutenção na web da circulação destas imagens. O corpus é composto de três vídeos sobre a morte de Osama Bin Laden. O que se busca responder é qual o papel desse jornalismo que emerge dentro da midiatização?

Palavras-chave Imagem, jornalismo, midiatização, memória, internet.

Abstract This article intends to investigate how the process of circulation of intermediatic images occurs. It is assumed the idea that many journalistic images are re-appropriated and re-entered in the media coverage itself, so that the individual iconographic memory is being replaced or fed from the maintenance of these images on web circulation. The corpus is composed of three videos about the Osama Bin Laden's death. What we are seeking to answer is what is the role of this journalism which emerges within the media coverage?

Keywords Image, journalism, media coverage, memory, Internet. 


\section{Objetos em jogo x jogo de objetos na web}

As imagens cada vez mais têm cercado os homens, tanto que Hans Belting chegou a defender a tese de que a sociedade da imagem não é uma sociedade contemporânea ou tampouco fruto de um século de imagens. Ao contrário, antes mesmo da era da arte, teria existido a era da imagem. Deste modo, pensar o momento atual onde as imagens se proliferam em dispositivos diversos, desde blogs a jornais impressos, é uma necessidade latente. Essa necessidade se manifesta de um lado na crescente escalada das imagens técnicas, para adotar o termo cunhado por Vilém Flusser, e de outro no uso replicante das imagens jornalísticas por dispositivos que não são, essencialmente, de instituições midiáticas jornalísticas. Isto é, vivemos um momento onde a midiatização já está arraigada na cultura, sendo comum, por exemplo, que um estudante de 15 anos faça um vídeo e poste no youtube e nos dispositivos que partilha para contar sobre algo de seu dia ou para manifestar seu posicionamento frente à questão política da liberação da maconha. Tome-se como exemplo a última campanha eleitoral no Brasil quando milhares de jovens produziram conteúdo demonstrando seus posicionamentos políticos. José Serra virou membro do Restart, Dilma um boneco de ventríloquo, contudo a criatividade aparente destas incursões midiáticas de atores cada vez mais midiatizados revela uma face importante para pensar o jornalismo contemporâneo. Assim como também é uma forma de pensar sobre o Brasil contemporâneo, as manifestações de junho de 2013 e as inúmeras reapropriações midiáticas efetuadas demonstram que os atores sociais se abastecem do produzido pelos chamados pelos mídias, mas cada vez mais ocorre também o contrário, em devorações múltiplas. 
Ao observar empiricamente os vídeos no youtube percebe-se que as imagens manipuladas pelos usuários da web são fotografias e vídeos inscritos em dispositivos jornalísticos em uma primeira instância, que são, em uma segunda, apropriados e recolocados em dispositivos diversos, reabastecendo, ciclicamente, a própria mídia, uma vez que este artigo adota a perspectiva da midiatização como a unificação e diferenciação dos mercados discursivos a partir de três dimensões que se afetam mutuamente: processos comunicacionais, contextos sociais e dispositivos. Entende-se, portanto, que a midiatização diz respeito às intersecções entre estes três elementos, sendo essencialmente uma questão de circulação, ora intra, ora entre dispositivos.

Deste modo, o que se pretende com este artigo é, a partir do conceito de midiatização, investigar como se dá o processo de circulação/circularidade das imagens intermidiáticas tendo como foco os afetamentos mútuos entre instituições não midiáticas e atores individuais que se valem das imagens fotojornalísticas produzidas. Parte-se do pressuposto de que muitas imagens jornalísticas são reapropriadas e reinscritas na própria midiatização, de modo que a memória iconográfica individual vai sendo substituída ou mantida a partir da manutenção na web da circulação destas imagens, numa espécie de memória protéica ou como afirma Anders (1994) "sparepieces" ou peças sobressalentes. Para compor o corpus de análise foram selecionados dois vídeos do youtube que serão decompostos a fim de identificar que tipo de imagens e lógicas os compõe. O que se busca responder é qual o papel desse jornalismo que emerge dentro da própria midiatização? $\mathrm{O}$ artigo está estruturado em três partes: a midiatização como objeto; a circulação das imagens fotojornalísticas e inferências sobre midiatização e memória na web.

2. Esta definição aparece no texto de Jairo Ferreira "As instituições e os indivíduos no ambiente das circulações emergentes" de 2011.

\section{Midiatização: circulação como centralidade}

A noção de midiatização vem sendo empregada em diversos estudos na área de comunicação, mas a sua definição continua um tanto difusa. Parte-se da ideia inicial de que a comunicação é uma forma de construir "zonas compartilhadas de sentido"2. Isto é, compartilhar os sentidos produzidos através das estratégias empregadas e pelas lutas travadas entre os campos sociais envolvidos no processo de comunicação. No entanto, vive-se hoje um cenário 
de midiatização, ou seja, a relação entre os processos sociais e comunicacionais que resultam na produção de sentido e, portanto, na comunicação, é atravessada por lógicas da mídia o que altera o modo de organizar a vida social.

Embora vários autores como Verón (2004), Muniz Sodré (2002), José Luiz Braga (2006), Jairo Ferreira (2007, 2008, 2009, 2011) e o próprio Fausto Neto (2008) discutam o conceito de midiatização, é de consenso o fato de que as mídias deixaram de ser meros suportes intermediários das relações entre esferas sociais e passaram a ser uma nova ambiência, uma nova forma de vida. Fausto Neto (2006) destaca que o conceito de midiatização emerge da própria comunicação que impõe sobre os demais campos suas próprias regras e lógicas, rompendo com os protocolos “clássicos" preestabelecidos. Deste modo é possível afirmar que a sociedade da midiatização é aquela onde a cultura dos meios é a referência da própria sociedade, regendo os processos e as trocas entre instituições e os atores sociais, instaurando "um novo modo de ser no mundo" como defende Pedro Gilberto Gomes (2005).

Neste sentido, Ferreira (2011) afirma que a midiatização diz respeito à unificação e diferenciação dos mercados discursivos a partir de três dimensões que se afetam mutuamente: processos comunicacionais, contextos sociais e dispositivos midiáticos. Cabe aqui uma ressalva importante, os dispositivos não são entendidos neste artigo apenas em sua dimensão técnica e tecnológica, mas, como um conjunto de materialidades e, ao mesmo tempo, um conjunto de intersecções entre os processos sociais e de comunicação. Isto implica dizer que os processos comunicacionais interferem nas relações entre dispositivos e processos sociais, ao mesmo tempo em que os dispositivos interferem nas relações entre processos comunicacionais e sociais.

Para Ferreira (2009) a midiatização só pode ser compreendida a partir da circulação. No entanto, ao frisar isto o autor propõe um contraponto à noção de circulação ou de feedback do sistema clássico de comunicação que significa retorno, uma vez que na circulação não há uma separação evidente entre produção e recepção, ao contrário, na esfera da midiatização estes papéis são constantemente alternados, o que será discutido mais a frente neste artigo em relação aos mecanismos do jornalismo online em relação às imagens. No 
entanto, cabe aqui ressaltar que há uma produção consumidora ao mesmo tempo em que um consumo produtivo.

Esse duplo processo produz diversas transformações nas disposições e dispositivos midiáticos, em suas relações com as instituições e indivíduos que os disputam, mobilizam e os desenvolvem. Os processos midiáticos somam, portanto diversas circulações - emissão/recepção, emissão/recepção/emissão e recepção/emissão/recepção transformadas pela midiatização das instituições (portais, novas configurações tipo Igreja Universal do Reino de Deus) e dos indivíduos (blogs, facebook, MSN). Todos, emissores e receptores, estão inclusos no processo de produção. (FERREIRA, ROSA: 2011, p. 03)

Avançando um pouco mais no esquema proposto por Ferreira e focalizando o olhar especificamente nas imagens, observa-se que há uma acentuação/alteração dos sentidos em função da circulação intermidiática, isto é, as fotografias jornalísticas, foco deste trabalho, não apenas figuram intra dispositivos midiáticos, mas também aparecem de modo reverberador em dispositivos não jornalísticos como blogs e no próprio youtube. Isto demonstra que a circulação é agenciada pelos dispositivos.

\section{FM: função memória ou função da mídia?}

O imaginário é constituído de imagens já vistas e que de alguma forma se tornam acessíveis. Ao reproduzir imagens ou reinscrever fotografias e vídeos em dispositivos midiáticos jornalísticos ou de atores sociais midiatizados, o imaginário está sendo fomentado e construído. Tome-se como exemplo a captura de Osama Bin Laden onde as imagens do World Trade Center foram reinscritas no circo midiático de modo enfático. Isto significa que as imagens veiculadas na mídia, seja em jornais impressos ou em sites, acabam por promover e organizar o imaginário coletivo, não apenas por sua exibição como parte da notícia, mas principalmente por sua inscrição na circulação intermidiática ou interdispositivos. Neste aspecto, Bystrina (1995) distinguiu as imagens em dois grupos: as 
3. Um exemplo disso são as galerias de imagens e os grupos de fotos da semana, bem como a possibilidade de links para sites diversos e agencias de notícias. Apesar disso, sabe-se que o jornalismo por ser jornalismo possui limitações espaciais se não de linhas, de caracteres. Contudo no online, há mais possibilidade de aprofundamento e adensamento por meio de hiperlinks e da convergência midiática. endógenas, ou seja, interiores, e as exógenas, as exteriores. Em uma sociedade essencialmente midiatizada, percebe-se que as imagens exógenas fomentam as endógenas, de tal modo que elas próprias passam a existir no imaginário.

O repertório iconográfico individual é formado por imagens que se acumulam e que estão acessíveis não apenas mentalmente, mas principalmente na própria web. Desta forma o repertório individual é uma soma de imagens mediadas, portanto, do não vivido, com as experiências reais, da ordem do vivido. Têm-se aí uma questão importante identificada nos materiais empíricos que serão apresentados a seguir. Há uma circularidade evidenciada nos dispositivos jornalísticos das mesmas fotografias, o que denota uma espécie de crise da visibilidade, pois há, de um lado, uma profusão de imagens e, de outro, a divulgação de um número cada vez menor nos meios massivos. Porém, o jornalismo online possibilita, teoricamente, pela não delimitação de espaço-físico, uma gama maior de visões do mesmo tema ${ }^{3}$.

$\mathrm{O}$ que se percebe nos portais jornalísticos ou nas publicações digitais é que esta gama ainda está demasiadamente atrelada àquelas imagens que já foram inscritas na circulação. Ou seja, mesmo com um potencial ampliador, de abertura de janelas, os sites jornalísticos seguem as lógicas dos dispositivos jornalísticos tradicionais. A pergunta seria por quê? Uma das respostas possíveis é a de que isso ocorre porque o imaginário coletivo é produzido pela mídia que estimula a criação de uma memória coletiva. Não mais no contexto massivo clássico, mas agora no contexto da midiatização onde usuários possuem um papel tão importante quanto o do próprio jornalista.

Quanto à memória, São Tomás de Aquino (apud SMOLKA, 2000) formula três regras: "1. a memória está ligada ao corpo (sensações, imagens); 2. a memória é razão (ordenação, lógica); e 3. a memória é hábito de recordar (meditação preserva a memória)". Deste modo, a memória é o resultado do processo de colocar as imagens em ordem e essa ordenação racional se dá por meio do hábito, sendo este regido pelos dispositivos. Assim, o que se coloca em discussão neste artigo é como as mídias digitais, em especial o youtube, desempenham, gradativamente, a função memória ao se constituírem no arquivo de imagens que coincidem com aquelas que arquivamos mentalmente. 
4. Mídias terciárias são aqueles que exigem um aparato tecnológico tanto por parte do emissor quanto do receptor da mensagem. Enquadram-

se neste caso a televisão, o rádio e mais recentemente os meios on-line. Pela classificação de Pross, as mídias primárias são aquelas que não exigem aparatos, exceto o próprio corpo como suporte. Já os meios secundários são aqueles que demandam um aparato para emissão, caso da fotografia.

\section{Entre o descarte e a permanência}

Os meios de comunicação como um todo possuem a possibilidade de fornecer imagens e textos verbais que podem vir a fazer parte da memória do homem. No entanto, as mídias terciárias digitais ${ }^{4}$, recorrendo à definição criada por Harry Pross (1980), parecem ter esta potencialidade ampliada, uma vez que permitem o processo contrário ao que ocorre com as mídias secundárias que é o descarte. O jornal impresso, por exemplo, é feito para ser descartado, visto que a efemeridade de suas informações dura até a chegada da edição seguinte. Nas mídias terciárias digitais o processo é diferente, pois se tem um constante banco de dados onde fotografias velhas podem ser vistas como se fossem novas, às vezes até retomadas, recortadas e incluídas em contextos completamente diversos dos originais.

Os jornais on-line, por exemplo, a Folha de São Paulo, mantêm uma galeria de imagens de notícias que já foram veiculadas, sendo que estas imagens estão agrupadas por categorias ou em "arquivos" especiais, caso do 11 de setembro, do acidente de avião da TAM, dos atentados em Madri e Londres, etc. Estas galerias não são apenas arquivos, mas elas são formas de eternização dos modos de visão destes fatos. É certo que estes espaços de veiculação de fotografias e vídeos são atualizados, segundo a lógica da própria web de mutabilidade, porém sabe-se que muitas notícias são "requentadas" e que pela capacidade tecnológica de arquivamento, os dispositivos jornalísticos criam "baús online" de memórias visivas, permitindo o acesso a qualquer momento.

Desta forma, os meios de comunicação, com ênfase aqui nos online, podem contribuir para a "amnésia coletiva", pois criam e fortalecem uma memória específica, baseada em determinados fatos que devem ser lembrados. Para a autora Myrian Sepúlveda dos Santos (2003), a memória é um processo social em que indivíduos isolados interagem uns com os outros, definindo o que deve ser lembrado e o que pode ser esquecido. Entretanto, cada vez mais esse processo social se dá através dos dispositivos midiáticos com a participação dos atores individuais midiatizados que também se inserem neste processo de criação de ecos visuais. Em relação à mídia, Mônica Rebecca Ferrari Nunes (2001, p.23) lembra que por seu papel de armazenamento de informações ela poderia ser considerada como "toda a memória do mundo". 
Ecos visuais no youtube | Ana Paula da Rosa

5. Os vídeos foram analisados em conjunto com o aluno de graduação Rayson Ferreira Barreto, bolsista de Iniciação Científica, e graduado em Rádio e TV pela Universidade Tuiuti do Paraná.

\section{Inscrições e reinscrições: Osama Bin Laden e suas faces}

Partindo da ideia de que a web, assim como a mídia, é um espaço infinito de armazenamento de dados, observa-se que a função memória é ampliada neste meio uma vez que é possível acessar materiais já há algum tempo desaparecidos ou mesmo criar novos produtos a partir de outros já disponíveis. Neste sentido, no que tange às imagens percebe-se que as inscritas em dispositivos midiáticos jornalísticos como revistas, jornais e na própria televisão, por exemplo, voltam a ser inscritas em dispositivos de atores individuais potencializando a circulação intermidiática. Isto pode ser percebido nas análises exploratórias que dão conta do corpus que é formado por dois vídeos produzidos por atores individuais disponibilizados no youtube e um quadro do Fantástico, programa da Rede Globo, veiculado semanalmente, que aborda exatamente estas inscrições midiáticas tendo como tema a morte de Osama Bin Laden.

Como percurso metodológico este artigo adota a visão de Charles Sanders Peirce (2003) sobre o método como um movimento, isto é, uma sequência de raciocínios entre o dedutivo, o indutivo e o abdutivo. Assim, os materiais serão mobilizados na tentativa de compreender e identificar os mecanismos utilizados para inserir/ reinserir as imagens jornalísticas em outros espaços. Para tanto os vídeos foram analisados ${ }^{5}$ de modo dissociado quanto a categorias de imagem, edição, efeitos entre outras, sendo que numa segunda instância estas serão relacionadas entre si. 
Artigos

\author{
Análise Osama 1: Título - Foto Osama Bin Laden Morto
}

\title{
Assista 0 vídeo
}

Fonte: http://www.youtube. $\mathrm{com} /$ watch?v=rrNbGEDc_

XQ\&feature $=$ related Figura 1- Foto Osama morto

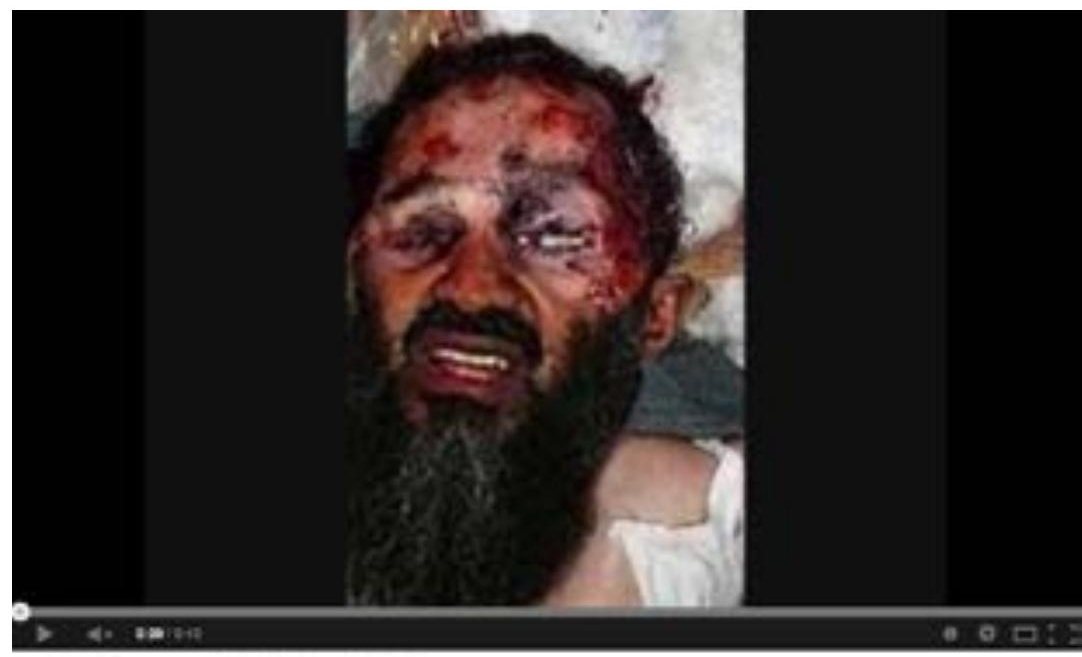

Foto Osama Bin Laden Norto.

\section{Quanto à imagem}

Nesse vídeo o ator individual faz uso de seis imagens estáticas, já midiatizadas. Cinco dessas fotos são de Osama Bin Laden e uma do atentado do dia 11 de Setembro ao World Trade Center, o que já demonstra uma reaproximação das duas temáticas. Dessas seis imagens, uma delas é empregada por duas vezes, que é supostamente a imagem de Osama Bin Laden morto. Ao utilizar esta imagem em duplicidade, observa-se que o sentido atribuído ao discurso já apresentado anteriormente pelos dispositivos jornalísticos é replicado, uma vez que todas as fotos que compõe tal vídeo já foram reproduzidas no meio jornalístico, como por exemplo, em jornais e revistas.

\section{Quanto à edição, efeitos e trilhas}

A edição foi feita de maneira muito simples, em um formato chamado "slide-show", onde basta ter um computador e um programa bem simples, como o Windows Movie Maker, para realizar a edição. Foram utilizados efeitos básicos de Zoom, ou seja, aproximação e afastamento das imagens no vídeo. Os recursos de edição 
empregados revelam que o conhecimento antes restrito à lógica dos meios, agora está cada vez mais acessível aos atores individuais que também se midiatizam, ou seja, não é necessário um domínio pleno da tecnologia, contudo é preciso a predisposição para ingressar na esfera da midiatização e, portanto, desejar ser visto.

$\mathrm{O}$ autor do vídeo utilizou efeitos de tiro, retirado de um jogo popular na Web, o Counter Strike, que fica em todo o tempo do vídeo fazendo repetições de efeitos de metralhadoras e fuzis. Os recursos são bastante simples, muitos já disponibilizados na própria web ou nos jogos. Há, portanto, um cruzamento de apropriações, elas não se restringem somente ao que é jornalístico, mas englobam também elementos de outros dispositivos e de outros espaços partilhados.

\section{Quanto aos créditos}

Não existe qualquer tipo de créditos referentes às imagens utilizadas pelo autor. Apenas o nome do usuário do vídeo: MultiScorpion2012, contudo identificou-se que todas as imagens estão disponíveis em vários dispositivos e no próprio google.

\section{Assista o vídeo}

Fonte: http://www.youtube.com/ watch?v=VqmtIWLe4PQ\&feature $=$

related

Figura 2- Osama não morreu

Osama 2: Título - Osama Bin Laden não está morto! Foto do corpo é falsa

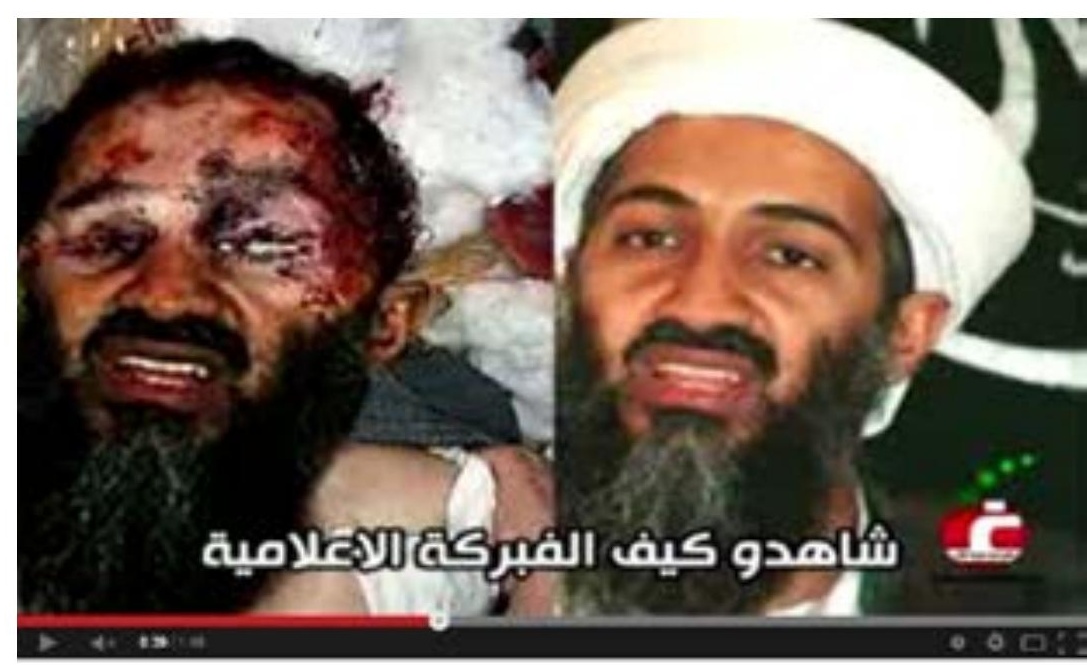

OSama EIN LADEN NAO ESTA MORTO 
Nesse vídeo o autor faz uso de três imagens estáticas com grande repercussão na mídia, todas elas fazendo referência à morte de Osama. A primeira é a imagem dele supostamente morto, a segunda é uma comparação dessa imagem "vazada" com uma fotografia de Osama vivo. Já a terceira é uma imagem dividida em três: a de Osama vivo, um homem morto, que teria servido de inspiração para a criação da terceira que é a montagem em si, ou seja, o suposto Bin Laden morto.

Estas três imagens também foram amplamente repercutidas pelas instituições midiáticas, sendo que a montagem foi apresentada pela primeira vez pela CNN, rede de TV americana, que posteriormente teve de se retratar publicamente. No entanto, independente das questões éticas e legais a fotografia que teria vazado do líder taleeban morto foi inscrita em diversos dispositivos de instituições com fins jornalísticos ou não, sem que sua autoria esteja clara. Isto implica dizer que numa sociedade midiatizada as imagens circulam e adquirem espaços impensados, ganhando vida própria, numa expressão que Vilém Flusser chama de não-coisas, isto é, as imagens podem se referir a objetos e cenas que nunca estiveram verdadeiramente lá, como afirma Barthes (1980), mas que de alguma forma foram tornadas existentes.

\section{Quanto à narrativa}

É um vídeo bastante crítico que faz uso de texto verbal para explicar a montagem de uma imagem de Osama Bin Laden morto que foi veiculada na $\mathrm{CNN}$, rede de grande tradição jornalística, mas que fez uso de uma imagem fake. O texto verbal disposto em inglês e com tradução em português aponta a rede americana como mentirosa e como uma fonte de descrédito. O discurso soa como um alerta frente ao jornalismo massivo, o mesmo que o autor toma como base para produzir seu vídeo.

\section{Quanto à edição, efeitos e trilha}

Como no vídeo anterior a edição foi feita de maneira muito simples pelo usuário. A diferença é que nesse vídeo o autor faz uso de caixas de texto em fade-in e fade-out (efeito utilizado também nas imagens) para expressar uma opinião de crítica ou reforçar o 
posicionamento. Já a trilha utilizada é a "New Religion" de autoria de Aalborg Soundtracks. A trilha mantém-se no mesmo tom de volume do começo ao fim do vídeo e não possui qualquer tipo de edição, ou seja, ela é usada apenas como complemento do vídeo, para intensificar o seu efeito.

\section{Quanto aos créditos}

Não existe nenhum crédito das fotos evidente, mas existe da trilha sonora, uma vez que o youtube exige tal crédito para não incorrer em violação de direitos autorais. O nome do usuário que postou o vídeo é TheGustavocm.

Reinscrição no jornalismo: Detetive Virtual desvenda os mistérios de supostas fotos de Bin Laden morto

O Detetive Virtual é um quadro do programa Fantástico da Rede Globo, que desvenda os mistérios da internet, na maioria das vezes com fotos e vídeos fakes. Neste, sobre a morte de Osama Bin Laden, postado pelo usuário worldnewbrasil, o quadro mostra como foi feita a montagem de duas imagens de Osama morto que caíram na web, logo após sua morte. O objetivo é desvendar como a imagem foi feita e desconstruir o seu processo de midiatização. 
Fonte: http://www.youtube.com/ watch?v=OXIZhaljf7c Figura 3- Detetive Virtual/ Rede

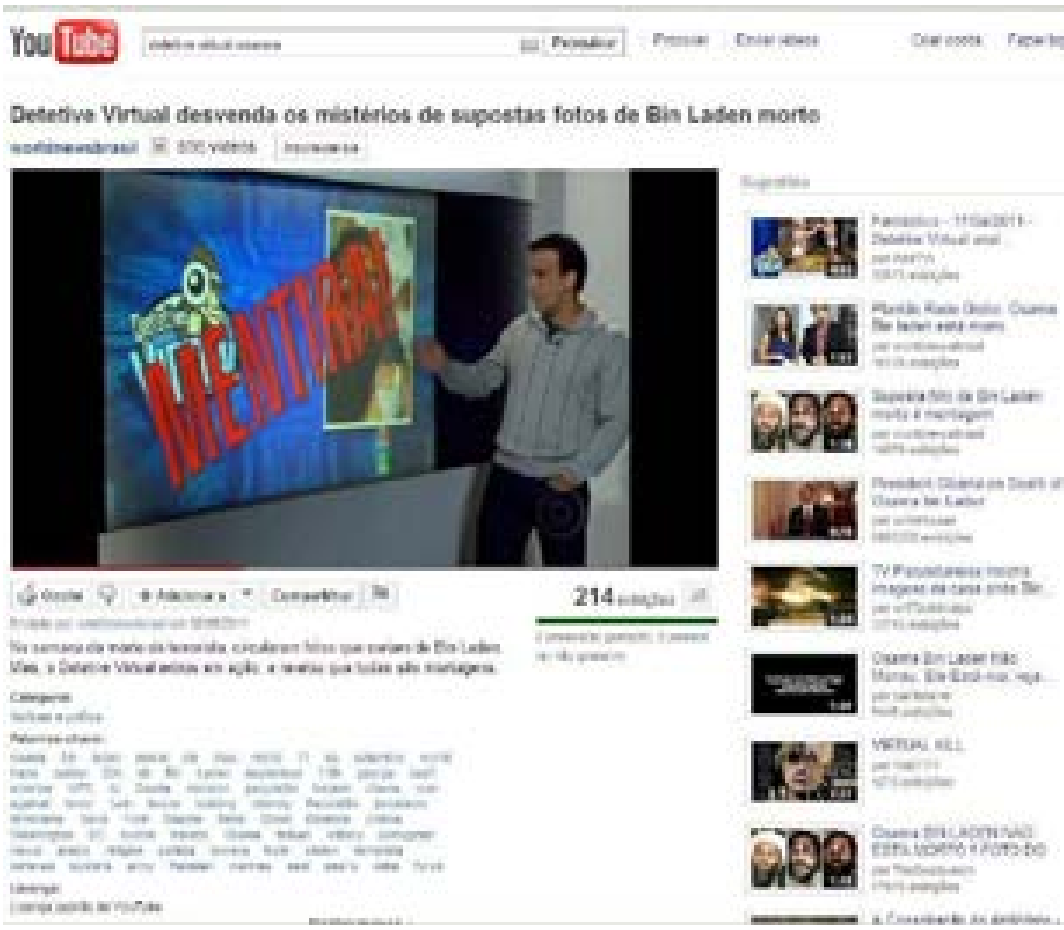

A primeira imagem é a famosa foto de Osama supostamente morto. Tadeu Schimdt, que apresenta o quadro, explica como foi feita a montagem. Uma foto de Osama vivo já circulada pela mídia nos anos 90 e uma imagem de um homem morto, também nos anos 90, divulgada pelas agências de notícias, são tomadas como base para a montagem. A desconstrução evidencia que apenas a parte debaixo da foto de Osama vivo é sobreposta na parte debaixo da imagem do homem morto, comprovando a foto fake de Osama Bin Laden morto. Ou seja, o "autor" da montagem apropriou-se de duas imagens desconexas e com recursos digitais sobrepôs as fotografias de modo a unificar o homem morto com a imagem de Osama, formando a fotografia do líder terrorista morto.

A polêmica da divulgação ou não das imagens de Osama pelo governo americano, portanto, por uma instituição não-midiática, fez com que uma dezena de imagens fakes fosse criada e inserida no circo midiático, porém apenas algumas obtiveram destaque, como foi o caso dessa imagem referida anteriormente que se tornou motivo 
de replicação em inúmeros dispositivos de atores sociais e em espaços jornalísticos da mídia tradicional.

A segunda foto apresentada no programa global relacionada à morte de Osama é uma montagem mais ousada. O usuário utilizou uma cena de um filme famoso de guerra, intitulado "Falcão negro em perigo". Neste frame selecionado um homem morto está nos braços de um soldado americano. Para representar a captura do terrorista, a imagem foi feita de maneira simples, inverteu-se a posição da foto e no lugar da cabeça do homem morto em combate, colocou-se uma foto da cabeça de Osama, como se Bin Laden estivesse morto nos braços do soldado. Esta montagem perde em termos de impacto para a imagem primeira, contudo demonstra um processo mais rico de produção, centrado também na questão memória, uma vez que poucos relacionariam a imagem de Osama com o filme. Além disso, ocorre uma etapa de edição mais intensa e de tentativa de recriar o "flagrante delito", ou seja, a captura em ato.

Neste quadro do Programa Fantástico as imagens que circulam na web são reveladas por meio de pesquisas e entrevistas, também de modo a tentar responder como são feitas as principais montagens e trucagens disponíveis, atribuindo a indicação de verdadeiro ou falso. Muitas vezes o vídeo alerta a população que imagens fakes existem e estão inseridas no mundo virtual. É como se o próprio jornalismo figurativizado no repórter alertasse que é preciso tomar muito cuidado com o que é revelado nesse mundo digital. O alerta, porém, serve inclusive para o jornalismo, pois se sabe que uma das maiores fontes de pesquisa para o jornalismo atual é a internet, o famoso gatewatching. Mais do que isso, ao apresentar vídeos e materiais produzidos por atores individuais dentro de um quadro jornalístico, ainda que focado no humor, percebe-se que a circulação intermidiática se dá não apenas no movimento emissão - consumo, mas cada vez mais no movimento inverso.

\section{Inferências sobre midiatização e memória}

Muitas imagens são distribuídas diariamente por agências de notícias e pelos próprios campos sociais envolvidos nos acontecimentos, contudo cabe às instituições midiáticas definir o que, efetivamente, será publicado na capa de um jornal, no índex de um site ou na televisão. Dito deste modo parece que esta função está 
restrita às organizações jornalísticas, por exemplo. Porém, são muitas as esferas em jogo para determinar qual imagem será escolhida e quais as razões pelas quais permanecerá circulando. Trata-se de um jogo de poder, mas um poder simbólico, disputado não apenas pelas instituições jornalísticas, mas essencialmente pelos atores individuais midiatizados que reinscrevem imagens, acrescentando camadas de sentido e mobilizando forças também perante outras instituições antes não convocadas.

No entanto, como o foco deste artigo não é tratar o poder simbólico, observa-se que após a análise individual de cada um dos vídeos é possível perceber semelhanças que denotam uma coleção, ou seja, todos os vídeos são composições de atores sociais que se autonomizam frente ao campo midiático, mas que se vale de imagens jornalísticas já vistas, num momento onde tais imagens são suscitadas pelo jornalismo. Contudo não há uma ideia de colaboração, mas de produção para a midiatização. As imagens, tanto do filme como do homem morto na década de 90, estão disponíveis online e permitem a montagem, a questão é o uso destas imagens com fins jornalísticos e não como mera ilustração ou cocriação em espaços próprios. Isto revela muito do jornalismo que se evidencia dentro da midiatização.

Assim, é possível dizer que as instituições midiáticas jornalísticas tornam-se, por conseguinte, receptores ou, nos termos de Jairo Ferreira (2011), executam uma produção consumidora, "apropriando as ofertas integradas a outros dispositivos, como parte importante da produção de seus dispositivos". Deste modo, os emissores passam a desempenhar a função de receptores de segundo nível, isto é, receptores de uma emissão por eles iniciada, mas acrescida de outras emissões. Em termos práticos, a imagem de Osama Bin Laden morto publicada na capa de jornais, em sites noticiosos e na CNN é também publicada em blogs pessoais, mantidos por anônimos, e, posteriormente, retomada em espaços jornalísticos gerando diversas circulações: emissão - recepção, depois emissão-recepção-emissão que gera recepção-emissão-recepção de modo ad infinitum.

No entanto, convém observar que nos materiais empíricos analisados a oferta de sentido que circula entre os dispositivos não sofre grandes alterações apesar das diversas circulações. Isto ocorre em função da inserção das mesmas imagens tanto em espaços jornalísticos como em não jornalísticos, sendo que as perspectivas são 
replicadas, mesmo sabendo que a web pode representar um espaço de contraponto amplo. Porém, mediante a ausência de uma imagem fiel que representasse a morte de Osama Bin Laden, a sua foto fake tornou-se tão simbólica quanto sua própria morte. De um lado o alerta de que o fato só existe quando é tornado um acontecimento jornalístico, isto é, o fato precisa ser registrado imageticamente, portanto, tornado existente. De outro, a eternização de Bin Laden como um terrorista, pois sem a fotografia de sua captura, ele é eternizado midiaticamente como um líder capaz de treinar pessoas para defender seus ideais com a própria vida indo contra todos os princípios ocidentais. Ou seja, as imagens que circularam de Osama refletem a posição de que os EUA estão certos, ainda que permaneça uma dúvida quanto a sua morte, o que pode legitimar a manutenção da caça aos terroristas no Oriente Médio.

Neste caso então, tem-se, de um lado, as instituições midiáticas jornalísticas construindo a cobertura imagética da morte do terrorista a partir da retomada da trajetória com ênfase no 11 de setembro. De outro, o governo americano impedindo o acesso da imprensa ao local da emboscada e não disponibilizando imagens do fato sob a alegação de que seriam fortes demais. Num terceiro movimento observamse, ainda, os atores individuais repetindo as imagens publicadas por instituições midiáticas ou produzindo vídeos a partir delas. Assim, tem-se disputando as lógicas de visibilidade: a) instituições midiáticas jornalísticas; b) instituições não midiáticas e c) atores individuais, sendo que as três instâncias recorrem a dispositivos midiáticos para afetar umas às outras. Assumimos aqui, portanto, que, em nossa perspectiva, há um reconhecimento da midiatização como lugar de interação social e de construção /abastecimento da memória.

\section{Considerações Finais}

Ante o exposto é possível afirmar que pelo domínio dos dispositivos os atores individuais também são empoderados, gerando uma relação nova, pois a reinscrição de uma imagem jornalística faz com que esta torne-se a única a ser vista, reforçando o processo de seleção feito anteriormente pela instituição midiática, e, obviamente reforçando o processo de exclusão das demais imagens que potencialmente estariam disponíveis para serem vistas. Deste modo, tem-se a imagem de Osama Bin Laden morto, sintetizada por uma fotografia 
da década de 90 onde ele aparece com um turbante branco e pela montagem que apresenta sua suposta morte, inserida em diversos dispositivos pertencentes às instituições midiáticas jornalísticas, para construir o discurso de que morreu o maior terrorista de todos os tempos. Posteriormente, estas imagens passam pelo reconhecimento e são reinseridas em dispositivos midiáticos partilhados por atores individuais, sendo que este movimento implica na determinação do tempo de duração de uma imagem na mídia e, principalmente, na própria web. Isto se dá a partir do momento em que a imagem passa a circular entre dispositivos, ampliando sua força de pregnância.

Neste aspecto, Ferreira $(2011,2008)$ argumenta que a inscrição dos discursos institucionais e dos indivíduos em dispositivos midiáticos inseridos na circulação, seja consumo-produtivo ou produção-consumidora como abordado anteriormente, transforma a própria circulação midiática, propondo novos modos de regulação dos processos discursivos das instituições midiáticas. Em outras palavras, ampliam-se, no momento atual, os espaços de interação e suas ocorrências, porém, há forças inerentes aos elementos em jogo que continuam atuando.

Entende-se, portanto, que na circulação midiática os papéis se equilibram o que demanda uma nova forma de pensar o jornalismo, não mais centrado em si mesmo e na informação simplesmente, mas focado naquilo que circula a partir da emissão primeira. Isto é, a notícia deixou de ser estanque (se é que foi um dia), não basta sua publicação. O valor notícia está exatamente na reinscrição desta em dispositivos diversos. Contudo, mesmo com a atuação cada vez mais incisiva dos atores individuais na web, percebe-se que o papel de agendamento do jornalismo continua em destaque, pois as produções são feitas a partir de materiais jornalísticos, tornando-os mais longevos que os próprios fatos.

Os dois vídeos de atores individuais analisados possuem em comum a exibição das mesmas imagens e a replicação daquilo que já foi midiatizado anteriormente. Ou seja, mais do que o acontecimento em si, a imagem ganha status de autorreferente. Quanto aos processos de edição e trilha empregados observa-se que são muito simples, a maioria recursos já disponíveis na própria web, porém mesmo na simplicidade é possível notar que as lógicas midiáticas estão presentes, afinal cidadãos comuns dedicam tempo e criatividade para produzir 
conteúdos que abordem de modo crítico ou não os fatos do cotidiano. Além disso, a interação via dispositivos fica evidente no momento em que o próprio jornalismo transforma em notícia a criação/ produção de montagens na web, ou seja, o próprio jornalismo se abastece do que é produzido por atores individuais.

Ainda há de se destacar que nunca foi tão necessário pensar as imagens como hoje. A memória vem sendo construída a partir da midiatização, uma vez que as imagens exógenas cada vez mais colonizam e compõe o imaginário individual, isto é, as imagens inseridas em dispositivos e que circulam entre e intradispositivos vão se acumulando de tal modo que se constituem em referências. Qual a imagem de Osama Bin Laden que permanece em sua memória? Quais as imagens do terrorista que ainda restam? O youtube pode ser a resposta, pois ele tem se constituído desde o seu surgimento não como um repositório virtual de materiais, mas como um backpup, uma memória externa, a qual permanece acessível constantemente. Ao acessar tal espaço, as memórias opacadas pelo tempo são reavivadas, porém são as memórias midiáticas.

Neste contexto, retoma-se a pergunta motivadora deste artigo: qual o papel desse jornalismo que emerge da midiatização? O papel é mais amplo do que se pode supor, de um lado a possibilidade de propiciar visões, ou restrições destas, sobre determinado fato, de outro o estabelecimento do fotojornalismo como tão ou mais importante que o texto verbal a ponto das imagens serem reapropriadas e reinscritas gerando novos e mais sentidos, muitas vezes minimizando os contextos, o que é sempre um risco. Portanto, o jornalismo que nasce na midiatização é um jornalismo que não se baseia apenas na fonte da notícia, mas no próprio processo de recepção, que em nossa perspectiva já se trata de uma nova emissão. Em outras palavras o jornalismo de hoje fomenta a memória, estimula a participação de atores individuais e é construído não apenas por jornalistas, mas a partir destes, com a missão de alinhavar os discursos e de atribuir sentido ao que circula, uma vez que o youtube vem se tornando um propagador de ecos visuais e uma memória prótese que não permite mais esquecer. Retomando Flusser (2007) o trabalho da comunicação e da mídia é "devorar para criar vazios devoradores", ou seja, devorar imagens para gerar mais imagens para o consumo e vice-versa. 
BAITELLO JUNIOR, Norval. O animal que parou os relógios: ensaios sobre comunicação, cultura e mídia. São Paulo: Annablume, 1999, reimpressão 2003.

A era da iconofagia: ensaios de comunicação e cultura. São Paulo: Hacker Editores, 2005.

BARTHES, Roland. A câmara clara: nota sobre a fotografia. Rio de Janeiro: Nova Fronteira, 1980.

BELTING, Hans. Pour une anthropologie dês images. Paris: Gallimard, 2004.

BYSTRINA, Ivan. Tópicos de semiótica e cultura. São Paulo: Cisc, 1995

BRAGA, José Luiz. A sociedade enfrenta sua mídia. Dispositivos sociais de crítica midiática. São Paulo: Paulus, 2006.

Midiatização: prática social, prática de sentido. Paper, Seminário Mediatização. Bogotá, 2005.

FAUSTO NETO, Antônio. A midiatização jornalística do dinheiro apreendido: das fotos furtadas à fita leitora. Disponível em <www.compos.org.br/biblioteca 245pdf $>$. Acesso em 20 jul. 2008.

. "Dispositivo de telecura e contratos de salvação". In: Comunicação, mídia e consumo. Ano 3, V. 3, n 6. São Paulo: ESPM, 2006.

FERREIRA, Jairo; VIZER, Eduardo (orgs). Mídia e movimentos sociais: linguagem e coletivos em ação. São Paulo: Paulus, 2007.

"Espaço crítico no jornalismo para além da indústria”. In: Metamorfoses Jornalísticas II: a 
reconfiguração da forma. (Edunisc , 2009)

Um caso sobre a midiatização: caminhos, contágios e armações da notícia. In: Midiatização e processos sociais na América Latina. São Paulo: Paulus, 2008.

FERREIRA, Jairo. "As instituições e os indivíduos no ambiente das circulações emergentes". MARCHIORI, Marlene. Faces of culture and organizational communication. 2011..

; ROSA, Ana Paula. "Midiatização e poder: a construção de imagens na circulação intermidiática”. IN: TEMER, Ana Carolina Rocha (org). Mídia , Cidadania e Poder. Goiás: UFG, 2011.

FLUSSER, Vilém.O mundo codificado: por uma filosofia do design e da comunicação. Organizado por Rafael Cardoso. São Paulo: Cosac Naify,2007.

GOMES, Pedro Gilberto.O processo de midiatização da sociedade. Sem data, sem referência.

Os processos midiáticos como objeto de estudo. IN:______ Tópicos da teoria da Comunicação. São Leopoldo: Unisinos, 2004.

KAMPER, Dietmar. Imagem. In: Cosmo, Corpo, Cultura: Enciclopédia Antropológica. A cura de Christoph Wulf. Milano, Itália: Ed. Mondadori, 2002

NUNES, Mônica Rebecca Ferrari. A memória na mídia: a evolução dos memes de afeto. São Paulo: Annablume, 2001.

PEIRCE, Charles. Semiótica. São Paulo: Perspectiva, 2003.

PROSS, Harry. Estructura simbólica del poder. Barcelona: Gustavo Gilli, 1980.

Fragmentos de um tecido. São Leopoldo: Editora Unisinos, 2004. 
SANTOS, Myrian Sepúlveda dos. Memória coletiva e teoria social. São Paulo: Annablume, 2003.

SMOLKA, Ana Luiza. A memória em questão: uma perspectiva histórico-cultural. IN: Educação e Sociedade, $\mathrm{n}^{\circ}$ 71, Campinas, v.21, jul. 2000. Disponível em: <www.scielo.br/ scielo>. Acesso em: 03 nov. 2006.

SODRÉ, Muniz. A narração do fato: notas para uma teoria do acontecimento. Petrópolis, Rio de Janeiro: Vozes, 2009.

As estratégias sensíveis: afeto, mídia e política. Rio de Janeiro: Vozes, 2006. 